\title{
"JORNAL PAPEL": DOCUMENTO E DISPOSITIVO PEDAGÓGICO*
}

\author{
Guaracira GouvêA* \\ Melanie Pimenta ${ }^{* * *}$ \\ ISADORA ScheER CASARI ${ }^{* * * *}$
}

\begin{abstract}
RESUMO: Os jornais estão presentes na escola em diversas situaçôes didáticas, reforçando o papel da leitura e da escrita como definidoras de uma cultura escolar. É nisso que se fundamenta a escolha do jornal impresso como objeto de estudo. Nosso foco voltou-se para a relação texto verbal escrito e texto imagético constitutiva dessa mídia nas seções dedicadas à divulgação da ciência, buscando compreender as relações entre esses textos, na formação de estruturas que explicitam determinados modelos de ciência e possibilitam o desenvolvimento de práticas educativas. Os jornais escolhidos foram os de grande circulação nacional, referentes ao período de 2006 a 2011. As leituras indicaram que a estrutura expressa na relação texto verbal e imagético tem marcadores no sentido de controlar a polissemia, mas em outros marcadores exploram possibilidades de diferentes leituras, encaminhando uma concepção de ciência afirmativa ou de ciência indagativa.
\end{abstract}

Palavras-chave: Jornal impresso. Divulgação científica. Imagem.

\footnotetext{
* Esta pesquisa foi apoiada pelo CNPq por meio de bolsa de produtividade de Guaracira Gouvêa e bolsa de iniciação científica (Pibic) de Melanie Pimenta.

** Programa de Pós-Graduação em Educação da Universidade Federal do Estado do Rio de Janeiro (Unirio). Rio de Janeiro (RJ) - Brasil.

*** Escola de Educação da Universidade Federal do Estado do Rio de Janeiro (Unirio). Rio de Janeiro (RJ) - Brasil.

**** Instituto Villa Lobos da Universidade Federal do Estado do Rio de Janeiro (Unirio) Rio de Janeiro (RJ) - Brasil.

Contato com as autoras: <guaracirag@uol.com.br>
}

Cad. Cedes, Campinas, v. 34, n. 92, p. 17-33, jan.-abr. 2014

Disponível em <http://www.cedes.unicamp.br $>$ 


\title{
NEWSPAPER: PAPER, DOCUMENT AND PEDAGOGICAL APPARATUS
}

\begin{abstract}
Newspapers are inside schools reinforcing the role of reading and writing as components of a school culture, which made us choose the newspaper as an object of study. The focus was the relationship between text and image at the sections dedicated to the popularization of science, by which it is possible to investigate how they establish structures that make certain models of science explicit and enable the development of educational practices. The newspapers that were chosen are of large national circulation. We analyzed the samples from 2006 to 2011, noting that sometimes the structure expressed in the relationship between text and image has markers in order to control polysemy but in other cases they stimulate other possibilities of readings. In the first case a conception of science without a doubt is defined, in the second case another way of understanding science takes place, more speculative and less rigid.
\end{abstract}

Key words: Newspapers. Popularization of science. Image.

\section{Mídia impressa e práticas educativas}

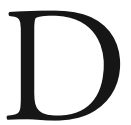

esde a criação da imprensa e de outras formas de reprodução (fotografia, filme, vídeo, entre outras) e meios de transmissão (telégrafo, telefone, antenas, televisão, rádio e a rede mundial), as relaçôes de uso pelos seres humanos desses aparatos técnicos criaram novas formas sociais de convívio, de entretenimento, de trabalho, de estudo que possibilitam a elaboração de novos conceitos e a releitura de outros, colocando-nos indagações frente a práticas sociais de educar.

É nessa perspectiva que nos demos como tarefa, nesta pesquisa, estudar o jornal impresso, uma tecnologia da informação e comunicação das mais antigas, e como parte integrante deste, a seção voltada para a divulgação da ciência. Estudamos a relação texto verbal escrito e texto imagético constitutivo dessa mídia, buscando compreender as relaçôes entre esses textos na constituição das estruturas que explicitam determinados modelos de ciência e possibilitam o desenvolvimento de práticas educativas em contextos escolares.

\section{Por que o jornal impresso?}

Estudo elaborado por Gouvêa (2012) nos informa que o jornal é, das mídias impressas, a mais estudada, seja por meio de seu uso nas escolas como 
material de ensino, na formação inicial de professores, nas representações que elabora acerca dos professores, da juventude, e da própria escola. Autores, como Zanchetta Jr. (2008), têm salientado a necessidade de se discutir os gêneros textuais dos jornais, pois estes já estão presentes na escola, seja no livro didático ou em atividades propostas pelos professores. As relaçoes escola e mídia são viabilizadas não somente porque a escola busca a mídia, mas também porque a mídia busca a escola, por meio de programas de incentivo à leitura de jornais, com objetivos de discutir a especificidade do gênero jornalístico e assim indicar situações didáticas possíveis com jornais. Vale citar que as empresas jornalísticas realizam oficinas com os professores, contribuindo para sanar uma lacuna na formação docente, no que se refere ao uso do jornal em sala de aula (PAROLI; ALMEIDA JUNIOR, 2006; CAVALCANTE, 1999). Os jornais estão presentes na escola em diversas situações didáticas, seja em sua materialidade ou em sua produção por estudantes. Dessa forma, reforçam o papel da leitura e da escrita como definidoras de uma cultura escolar, e nessas consideraçōes é que se fundamenta a escolha do jornal impresso.

\section{Por que a seção de ciência?}

Diferentes meios de comunicação em nosso atual modo de vida produzem e difundem saberes que estão mediados por arsenal tecnológico em constante transformação. Essas transformações estão intrinsecamente ligadas ao sistema de ciência e tecnologia, cuja penetração manifesta-se, de fato, em nossa vida cotidiana por meio de objetos que utilizamos e que são produtos da técnica e, por assim dizer, estão "impregnados de pensamento científico. Essa penetração é anônima, já que a maioria de nós ignora completamente os seus modos de intervenção [...] pois é fundamentalmente por intermédio do objeto técnico que a ciência nos toca em nossa vida cotidiana" (GRANGER, 1994, p. 16). Assim, pode-se indagar: como essas transformações permeiam a vida dos cidadãos? Como, por sua vez, eles se comportam diante delas? Será que os cidadãos, para decidirem sobre como organizar o seu cotidiano, no sentido de escolher técnicas e formas de operá-las e de conhecer os impactos que estas têm sobre sua saúde, meio ambiente e cultura, bem como na sociedade em que vivem, precisam ter acesso a esses conhecimentos?

No sentido de responder a essas indagações, a sociedade, por meio do sistema formal e não formal de educação, organiza ações educativas para a 
difusão de conhecimentos científicos e tecnológicos e busca tornar possível a elaboração de filtros de conhecimentos. Na escola, como na mídia, existem espaços reservados para que se abordem os conteúdos, temas e questōes relativos à ciência e a tecnologia. Há um consenso entre a comunidade científica, o sistema educacional formal e o não formal sobre a importância da difusão da ciência e da tecnologia (BUENO, 2001).

$\mathrm{O}$ jornal impresso não fica alheio a esse movimento e insere em suas publicações diárias seções voltadas para a divulgação da ciência. Em estudos como de Pretto (1991) e Gouvêa (2005), há fluxos e refluxos na existência dessas seções, mas, desde a década de 1990 até a data deste estudo, as seções sobre ciências estão presentes diariamente nos jornais de grande circulação nacional. Além deste aspecto, intensifica-se, a partir da década de 1970, a discussão acerca dos efeitos no meio ambiente, na saúde, nas formas de comunicação; na organização do trabalho e no entretenimento, isto é, em nossas relaçôes cotidianas, dos usos da ciência e da tecnologia, tornando os temas dessa área de interesse de muitos grupos sociais (MCT, 2010); ainda, ao criarem espaços para esses temas, os jornais se voltam para esses grupos.

Nosso conjunto de jornais analisados corresponde ao período (20062011), em que as açóes do governo - no que se refere à ciência e tecnologia - voltam-se para a implementação de um plano de desenvolvimento nacional que pretende, entre outros objetivos, aumentar a popularização e aperfeiçoar o ensino de ciências nas escolas. Afora essa consideração, na relação divulgação científica e escola, pesquisas indicam que a divulgação científica "assume múltiplas funções: informativa, educativa, social, cultural, econômica e político-ideológica. Complementa a educação formal e a responsabilidade de manter o interesse pelo conhecimento, pela atualidade de suas informações [...]" (GONÇALVES; CALDAS; PECHULA, 2011, p. 9).

\section{Papel-jornal}

Inspirando-nos em Dias (2007), pensamos: o jornal, objeto de nossa cultura material, é fragmentado, composto por unidades que se fecham em si - cadernos -, é diário, feito de papel-jornal, é descartável, é reciclado, é efêmero, se contradiz. No entanto, é documento, fonte de informação, é objeto da cultura material da Modernidade e com ela se modifica; e como objeto da cultura torna-se dispositivo pedagógico (FISCHER, 2002), pois indica possibilidades de educar nosso olhar sobre o mundo. 
Nessa perspectiva é que estamos considerando a mídia impressa, dispositivo pedagógico, documento e objeto material, constituída de textos verbais escritos e imagéticos que lhe confere uma identidade. $\mathrm{O}$ jornal é abordado como objeto material, testemunho de uma época, cujas expressóes simbólicas caracterizam as relações ideológicas de uma época e as relaçôes de poder e são constitutivas das significações e dos sujeitos, neste trabalho; significaçōes sobre a ciência que o caracteriza como dispositivo pedagógico. O jornal impresso é a materialização da articulação entre texto verbal escrito e imagético e indica um circuito para essa materialização. No entanto, o leitor pode burlar os mecanismos de controle contidos nesse circuito, pensados pelos idealizadores, e construir vários hipertextos. Isto significa construir múltiplas temporalidades, múltiplas sequências e ter para si diferentes objetos culturais, compartilhados no momento da leitura com outro leitor, ou posteriormente.

Gomes (1995, p. 27), ao falar dos textos jornalísticos, considera que a "ordem semântica desses textos não é determinada pela sequência dos fatos, mas pela coerência funcional baseada na relevância: o que é tido como mais importante ou interessante vem em primeiro lugar e as informaçôes secundárias e detalhes vêm por último”. Nesse sentido, o que é relevante para o leitor determina a ordenação semântica.

O texto jornalístico é de natureza expositiva: apresenta em níveis diferentes de profundidade o conteúdo da matéria. A construção de um texto jornalístico obedece rigorosamente aos cânones comunicacionais, em que claramente se privilegia o receptor. Este pode ler somente o sumário e obterá informaçôes que deverão estimulá-lo a fazer a leitura completa da matéria, passando pelos fatos e pela interpretação. A linguagem utilizada no texto jornalístico tende a se aproximar da linguagem do cotidiano, apoiando-se em metáforas e analogias para tornar as exposições mais claras.

Como estamos considerando as mídias constituídas de textos híbridos semióticos, e um dos componentes que caracteriza esse hibridismo são as imagens, necessitamos problematizar a própria categoria imagem.

\section{A imagem}

O termo "imagem" possui diferentes sentidos fundamentados em sua materialidade: imagens das artes plásticas (como as das pinturas, dos desenhos, das gravuras); as imagens veiculadas pelos meios de comunicação de massa (como as da televisão, das fotografias, dos filmes); as que aparecem na tela 
do computador, mas também podemos pensar em imagem mental, as que estão gravadas em nossa memória e que representam o nosso mundo cultural.

Neste estudo, a imagem será considerada como representação de uma coisa, em sua materialidade e, por ser representação, em sua convencionalidade. Para Barthes (1990), toda imagem possui duas mensagens: a denotada e a conotada e, ainda, se vier acompanhada por um texto, terá a mensagem linguística. A leitura de imagens é polissêmica, pode adquirir sentidos diferentes para leitores diferentes, ou para um mesmo leitor em momentos distintos, devido as suas experiências anteriores no contato, na percepção do mundo. A mensagem conotada requer, para seu entendimento, um conhecimento cultural; a mensagem linguística também funciona como método de conotação da imagem, pode enfatizar sentidos de conotação já presentes na imagem, produzir novos sentidos ou contradizer a imagem, tornando-a sempre uma convenção. Esta admite duas funçōes ao acompanhar uma imagem: de fixação ou de relais. A primeira está ligada diretamente ao aspecto polissêmico da imagem: o texto serve para guiar o leitor ao sentido preferencial da mensagem imagética, ou seja, no sentido de controlar a produção de sentidos, oriunda da intencionalidade do produtor da imagem. No relais, texto e imagem se complementam na compreensão da leitura de uma sequência de imagens (histórias em quadrinhos, por exemplo), no desenvolvimento de uma ação (imagens em movimento), apresentando os sentidos que a imagem sozinha não manifesta claramente (BARTHES, 1990).

A exemplo de outros textos contemporâneos, pode-se afirmar que, atualmente, o texto científico impresso típico é um híbrido semiótico (LEMKE, 1998), isto é, utiliza linguagem verbal escrita e elementos pictóricos e gráficos no mesmo espaço de página. Os manuais técnicos, os livros de divulgação, as revistas científicas ou de divulgação, os jornais, os livros didáticos e as páginas da internet contêm textos sobre conhecimentos científicos que recorrem às imagens com diferentes fins. Nesta investigação, estamos problematizando a relação texto verbal escrito e texto imagético, gravados em papel, e isso será realizado por meio da análise desse material, não da leitura por seus diferentes leitores, mas sim pela nossa leitura.

\section{O estudo}

Os jornais escolhidos foram os de grande circulação nacional e que têm seções dedicadas à divulgação científica. Assim, segundo dados da Associação 
de Jornais do Brasil, os jornais escolhidos foram Folha de S. Paulo e O Globo. Como o período de coleta era extenso - 2006-2011 -, decidimos realizar um estudo exploratório, recolhendo exemplares dos jornais escolhidos dentro de uma semana em 2006 e outra em 2011, para cada um dos jornais, e buscamos exemplares completos a fim de classificar a estrutura desses veículos. Depois da realização do estudo exploratório, definimos que não colecionaríamos os jornais de todos os meses do período, e como os jornais são diários e passaram a publicar seçóes de ciência quase todos os dias, realizamos uma escolha aleatória em um mês e em cada ano para nossas análises. Deste montante, selecionamos um conjunto que fosse formado por meses diferentes e que apresentasse imagens com formas de produção distintas, isto é, fotografias e infodesenhos (gráficos e esquemas). Este conjunto ficou formado por 524 exemplares da Folha de S. Paulo e 666 exemplares de $O$ Globo.

\section{Leituras possíveis}

Sobre a estrutura geral dos jornais, descrita com base nos exemplares de 2011, podemos informar que são constituídos de cadernos, denominados primeiro e segundo em $O$ Globo e cadernos $A, B, C, D, E, F$ na Folha de $S$. Paulo. Estes são agrupados nessa ordem, de modo que o leitor recebe o jornal ordenado por caderno. Isto significa que o leitor vê de imediato a primeira página do primeiro caderno, que contém a chamada das notícias consideradas relevante pelos editores, e pode separar os cadernos para leitura, conforme seu interesse. A ordem dos dois jornais tem alguns pontos em comum: a política nacional se constitui no primeiro tema apresentado, os outros temas se deslocam, mas com a mesma forma de agrupamento.

Os cadernos privilegiam uma temática. Na Folha de S. Paulo, no caderno Ilustrada, são apresentadas notícias sobre o movimento cultural nacional e a programação cultural do dia no que se refere ao estado de São Paulo, e o Segundo Caderno de $O$ Globo, que corresponde ao Ilustrada, mas apresenta uma agenda cultural vinculada ao estado do Rio de Janeiro. Uma diferença é que, na Folha de S. Paulo, há um caderno denominado Cotidiano que não tem correspondente em $O$ Globo. Neste são publicadas notícias nacionais e locais que interferem no cotidiano das pessoas, como trânsito, acidentes, obras, índices de violência. Em fevereiro de 2011, a Folha de S. Paulo passou a publicar a seção Ciência e a seção Saúde neste caderno; quando os assuntos se vinculam à seção Saúde, tornam-se Saúde+Ciência. A seção ciência em $O$ Globo está inserida no caderno Economia. 
No que se refere às táticas de apresentação dos temas de divulgação científica, selecionamos alguns indícios que podem nos levar a traçar consideraçôes de como a editoria desses jornais pensa a Ciência. Consideramos relevante destacar: o total de matérias publicadas na primeira página; o total de matérias publicadas com e sem imagens; as temáticas publicadas com maior recorrência e as mudanças nos projetos gráficos ao longo deste período.

De um total de 524 jornais analisados, a Folha de S. Paulo apresentou um total de 838 matérias no conjunto das seções analisadas. Destas seções, 197 foram publicadas nas chamadas na primeira página. Isto significa que $38 \%$ foram consideradas relevantes para terem espaço na primeira página, que representa o sumário do jornal sobre as notícias mais importantes. Das matérias publicadas ${ }^{1}, 60 \%$ tinham imagens vinculadas a sua informação. Das notas publicadas, notícias curtas, 53\% tinham imagens com legendas curtas. Os temas mais abordados foram: meio ambiente (285); astronomia (210); zoologia (175), política científica (160); os menos abordados foram: robótica (10); zootecnia (16); química (20) e bioética (26).

Quanto ao jornal $O$ Globo, foi analisado um total de 666 jornais, contendo 1.757 matérias, e foram contabilizadas 323 imagens. Em 666 seções de ciência, 72 foram publicadas com chamadas na primeira página, ou seja, $11 \%$ foram consideradas relevantes para terem espaço nesta página. Das matérias publicadas, $52 \%$ tinham imagens vinculadas a sua informação. Não há notas na seção de ciência de $O$ Globo. Os temas mais abordados foram: saúde (375); meio ambiente (340); astronomia (70); genética (60). Os temas menos publicados foram: zootecnia (5); agronomia (13); divulgação científica e política científica (21) e biologia marinha (24).

Analisando os dados apresentados, podemos traçar algumas considerações acerca do perfil dos jornais. Quanto à Folha de S. Paulo, a maioria das matérias e notas publicadas vem acompanhada de imagens, sendo que, em alguns casos, esta constitui a própria nota em si - são imagens que vêm acompanhadas de pequenos comentários. Quanto à variedade de temas ${ }^{2}$ publicados, percebemos que meio ambiente e astronomia são abordados com maior frequência; o tema saúde não aparece na Folha de S. Paulo, pois há uma seção específica para ele. No projeto gráfico do jornal percebemos algumas modificações ao longo destes seis anos. Em maio de 2006, a Folha Ciência recebe a denominação de Ciência. Além da modificação no título e na aparência da seção, as "notas imagens" começam a ser publicadas com maior frequência. A partir do mês de janeiro de 2008, a seção de Ciência 
passou a ser publicada diariamente, inclusive aos domingos. Nos anos anteriores, ela não era publicada neste dia. Em 2011, a seção Ciência passou para o caderno Cotidiano junto à seção Saúde e, a partir do mês de novembro de 2008, passaram a ser publicadas diariamente. Verificamos que, a partir deste mês, a primeira página dos jornais traz, muitas vezes, chamadas para Ciência e Saúde no mesmo dia. A seção de Saúde apresenta muitas imagens, desenhos e esquemas explicativos. Uma característica importante deste jornal é que, em muitos casos, ele traz pequenas "chamadas" para matérias "especiais" sobre ciência que vêm publicadas em outros cadernos ou na seção Mais! - seja em forma de caderno especial ou não. Também são frequentes pequenas chamadas convidando o leitor a buscar mais informações sobre aquele tema em seu correspondente online. No que se refere às imagens apresentadas, percebemos a publicação de esquemas explicativos e imagens com legendas com muita recorrência. As imagens, algumas vezes, fornecem as principais informaçôes sobre determinado tema, sem que haja necessidade de recorrer ao texto. Constatamos, ainda, que a Folha aborda com maior frequência assuntos relacionados ao fomento de pesquisas, premiações e políticas científicas que demonstram haver uma preocupação em informar a sociedade sobre essas questóes.

Quanto ao jornal $O$ Globo, percebemos que os temas publicados com maior frequência, nesse período, se assemelham aos publicados na Folha: meio ambiente e astronomia. Constatamos também que $O$ Globo não possuía uma seção dedicada exclusivamente à divulgação científica até o mês de fevereiro de 2007, quando esta passou a ter uma seção exclusiva de ciência. Anteriormente, as matérias relacionadas à divulgação científica eram publicadas na mesma página do caderno O Mundo. Em 2010, uma seção denominada História passou a integrar o conjunto de informações sobre a ciência.

Ambos os jornais sofreram modificações em seu projeto gráfico ao longo desse período, no sentido de tornar o jornal mais agradável ou, como no caso da Folha, acrescentar uma seção de divulgação científica exclusiva para a temática saúde, em 2010; a seção Ciência passou a fazer parte do caderno Cotidiano, o que pode indicar a perspectiva de inserir a ciência no cotidiano dos leitores ou de buscar um público usualmente não leitor desse tema, pela característica desse caderno.

Neste momento, apresentamos nossa leitura das relaçôes texto verbal escrito e imagético, de um conjunto de imagens selecionadas como relevantes 
"Jornal papel": documento e dispositivo pedagógico

e disponibilizadas na seção de Ciência dos jornais analisados. Para apresentarmos nossas leituras, optamos por citar alguns exemplos de determinadas categorias escolhidas, ora de um jornal, ora de outro.

FOLHA DE SÃO PAULO, SÁBADO, 26 DE ABRIL DE 2008

Ciência - Seção

Fotografia da ex-ministra do Meio Ambiente (Marina Silva) discursando

Legenda: "Desmate não resolve crise de alimentos, diz Marina"

Analisando a imagem, percebemos se tratar de uma mulher, no caso, à época, a ex-ministra do Meio Ambiente (Marina Silva), que fala em um microfone e seus gestos revelam uma expressão de preocupação, nervosismo, ou exaltação. Segundo Barthes (1990), a pose escolhida para se fotografar nos leva a conotar a imagem como um momento de descontentamento e desacordo da ex-ministra - a personagem se encontrava no momento do registro com a mão levantada, a fim de ressaltar o seu estado emocional diante daquele fato. Já a relação imagem-texto pode ser analisada como de fixação, onde a inclusão do texto à imagem indica um caminho de leitura da primeira. Se não recorrêssemos à legenda, ao título e à chamada, não conseguiríamos compreender o que se pretende evidenciar na fotografia, que, no caso, é uma reação da então ministra do Meio Ambiente, Marina Silva, em depoimento em resposta às declarações do governador do Mato Grosso acerca do desmatamento como solução à escassez de alimentos. Nesse sentido, a notícia informa sobre duas posiçôes em relação ao desmatamento, ambas apoiadas em dados científicos, o que nos leva a produzir múltiplos sentidos em relação ao fato do desmatamento.

As leituras possíveis dessa notícia nos indicam a não neutralidade do conhecimento científico, particularmente, nesse caso, de seu uso político na elaboração do discurso, cuja cadeia argumentativa pode levar a posturas a favor ou contra o desmatamento, produzindo significaçōes de uma ciência não afirmativa e mais indagativa. Outro aspecto é a possibilidade que essa matéria gera da realização de intertextos, na medida em que nos leva a outros temas como conservação ambiental e formas de produção de alimentos. Tanto as significaçôes geradas, como a possibilidade de se realizar intertextos nos levam a considerar o jornal como dispositivo pedagógico. No 
contexto escolar, essa notícia poderia se tornar um tema pra ser discutido em disciplinas diversas e com diferentes posiçóes políticas.

O GLOBO, QUARTA-FEIRA, 9 DE ABRIL DE 2008

Ciência - seção

Apresenta esquema explicativo das descargas elétricas - imagem- infodesenho

Legenda: "Conheça os tipos de descargas elétricas"

A imagem representa um esquema desenvolvido em um programa de computador que une imagens e textos a fim de explicitar um conceito. A imagem e as legendas constitutivas do esquema elaborado formam uma sintaxe de encadeamento, também denominada por Barthes (1990) de relais, que nos encaminha para um significado, no sentido de controlar a polissemia. É como nas tirinhas ou histórias em quadrinhos: estas só possuem lógica quando encadeadas e dispostas sequencialmente, cada quadro expressa atitudes e valores; quando reunidos, produzem novos sentidos às imagens. A relação imagem-texto é de complementaridade, explicitam algo dificilmente percebido na leitura dos desenhos isolados. Como o objetivo é explicar os tipos de raios, não se abre espaço verbal ou imagético para elaboração de outros modelos. É, assim, uma explicação afirmativa - a ciência diz isso. Não estamos deixando de considerar as possibilidades de outras leituras, mas os marcadores de intencionalidades do padrão-esquema nos levam a pensar em controle dos sentidos, o que nos aponta uma forma de educar.

O GLOBO, SÁBADO, 14 DE AGOSTO DE 2010

História - seção

Pirâmide - imagem-fotografia

Chamada da matéria: "O último segredo da pirâmide"

Legenda: "A GRANDE pirâmide de Gizé: construção de 4,5 mil anos ainda guarda mistérios"

Lead: "Robô vai explorar túneis na Câmara da Rainha, lacrados há 4500 anos" 
A imagem da pirâmide ocupa metade da página do jornal e é uma fotografia que a apresenta de frente em seus limites laterais, e se percebe as pedras que a compõem. Nesse sentido, essa imagem representa iconicamente uma pirâmide. A relação entre o texto verbal e a imagem, seja da chamada da matéria, seja legenda ou lead, é de fixação de sentido na busca por fatos que desvendem o mistério de algo sagrado, por isso um robô irá explorar. Isso nos leva a pensar que História é a busca pelos fatos passados. A forma de apresentação dessa notícia segue os parâmetros da linguagem jornalística, pois o caminho percorrido da leitura é: imagem, chamada, lead e legenda, e estes expressam uma representação que está na memória social dos leitores acerca das pirâmides - sagrado e mistério. As significações geradas nos indicam uma forma de olhar o mundo e assim têm um sentido de educar.

Esta é uma matéria que pode ser utilizada para se discutir o gênero jornalístico e qual é a concepção de história adotada.

\section{FOLHA DE SÃO PAULO, SÁBADO, 28 DE FEVEREIRO DE 2011 \\ CADERNO COTIDIANO - Saúde - Seção}

Chamada da matéria: "Nos EUA, nova proposta para doação de rim favorece jovens"

Subtítulo: "Objetivo do plano em discussão é que órgãos doados sejam compatíveis com idade do paciente"

Lead: "Críticos dizem que esquema não resolve os principais problemas dos transplantes e prejudica mais velhos"

Desenho dos rins e do rim transplantado em um recorte de ser humano, onde aparecem os ossos do quadril e coxas.

Ao lado há um texto em tópicos que explica como é a cirurgia de transplante de rins

Essa matéria pode ser lida por fragmentos, os blocos são independentes, e em relação à imagem que representa os rins e o rim transplantado, somente alguém com conhecimento prévio poderá compreender o representado na imagem, mesmo havendo indicações dos nomes das partes desenhadas. A discussão apresentada nos blocos escritos está clara, mas a imagem escolhida acrescenta informações que não entram na cadeia argumentativa da discussão proposta pela matéria. Nesse sentido, seria desnecessária, mas poderia ampliar o conhecimento dos leigos sobre esse órgão, por exemplo, 
sua localização no corpo humano. Como o tema está voltado para questôes éticas, trata a ciência de forma indagativa. Nesse texto, a discussão sobre a ética nas decisões em saúde seria um bom tema para ser abordado.

\section{$\mathrm{O}$ que percebemos}

Os discursos sobre a ciência, apresentados nas seções de Ciência dos dois jornais, seguem a superestrutura do texto jornalístico, desenvolvida por Van Dijk (1990), que contém sumário, onde se agrupam o título (chamada da matéria) e a abertura (lead) que, com o apoio do antetítulo, do subtítulo, das fotos e legendas, resumem o tópico principal da notícia e o relato jornalístico, que se desdobra em episódio e comentários, ou seja, os fatos reportados e sua interpretação. O texto jornalístico é de natureza expositiva, apresenta o conteúdo em níveis diferentes de profundidade da matéria e a ordem dos fatos atende um critério de relevância: o que é considerado mais importante é exposto em primeiro lugar. Essa ordem não é a mesma pensada pela ciência e, assim, há um embate entre os discursos materializados em linguagens e em gêneros distintos, o do discurso jornalístico sobre a ciência, denominado discurso da divulgação científica, e o da ciência, denominado discurso científico. Isso confere ao leitor a possibilidade de entrar em contato com outro olhar sobre a ciência e gerar significados.

A estrutura dos dois jornais impressos se mantém ao longo de suas ediçōes, ou seja, os mesmos cadernos apresentados e os padrões editoriais que verificamos são uma maneira jornalística de fazer com que o leitor reconheça o seu jornal. Assim, percebemos que aparência, cor e estrutura são estratégias que os jornais adotam para atrair e manter o leitor, e o conhecimento desses recursos influencia diretamente no uso do jornal no âmbito pedagógico, pois "é importante que o trabalho com jornal seja iniciado a partir da exploração de sua forma. Tendo contato com o material, conhecendo suas partes, sabendo onde buscar o assunto de interesse, o estudante achará a leitura do jornal mais fácil e atraente" (CAVALCANTE, 1999, p. 49). Além disso, o uso de gráficos é recorrente: tabelas e esquemas que não apenas auxiliam no entendimento, mas que, muitas vezes, podem ser lidas sozinhas sem que haja necessidade de recorrer à matéria escrita. É comum vermos também fotografias e legendas que constituem a matéria em si mesma, pois não vêm seguidas de texto escrito além do próprio comentário da imagem. Muitos dos conceitos científicos podem ser absorvidos se existem 
imagens explicativas que acompanhem as matérias, como fotografias espaciais, de equipamentos, animais e fósseis, por exemplo. Percebemos, ainda, que os enunciados que acompanham as imagens científicas só adquirem sentido quando estes se complementam mutuamente. Dessa forma, como nos aponta Schmidt $(2007$, p. 2), “[...] Falar na pedagogia da mídia, por exemplo, é compreender que ao lermos um jornal, ao olharmos uma novela, estamos aprendendo coisas, estamos sendo constantemente interpelados por discursos que nos conformam e nos subjetivam".

As imagens presentes nas seções de Ciências dos jornais analisados são signos linguísticos relevantes para o aprendizado de certos conhecimentos científicos, tanto no âmbito escolar, quanto em espaços não formais de educação. Ao interagir com a imagem e o texto, o leitor interage com os conceitos ali expressos, recorrendo ora ao texto, ora à imagem, no sentido da fixação explicitada por Barthes (1990). Assim, podemos inferir que a intencionalidade dos editores é de, além despertar o interesse pela leitura de notícias sobre ciência, controlar a produção de sentidos, na medida em que as relações texto escrito e imagem são de fixação ou de relais. Isto nos leva a considerar que está expressa, na maioria das vezes, uma concepção de ciência afirmativa e uma perspectiva de educar.

\section{Considerações}

Os padrões estéticos que conduzem a apresentação gráfica dos jornais estudados apresentam forte influência das mídias, constitutivas da cultura contemporânea, como a fragmentação dos textos, muitas caixas de textos, subtítulos, imagens coloridas com legendas, que indicam múltiplas possibilidades de leituras, curtas, aleatórias, mas não uma única leitura linear. Muitas leituras que atendem à demanda por contração do tempo; os conteúdos e as imagens oriundos do campo da ciência e da disciplina escolar Ciência também estão presentes. Percebe-se, então, que há um cruzamento entre culturas: a da mídia com a cultura escolar e a cultura científica. Na realidade, o outro, a cultura do outro, torna-se um recurso didático, na medida em que seu mundo cultural é chamado a participar das interaçóes, quando pode ser utilizado como argumento para desenvolver um modelo explicativo legítimo. Dessa forma, o jornal torna-se um dispositivo pedagógico.

Para Silverstone (2002), as mídias, materializadas em aparatos técnicos e simbólicos, jogam um papel fundamental nos sentidos produzidos em 
nossa vida diária, gerando e mantendo o senso comum. Para este autor, elas selecionam e hierarquizam as realidades cotidianas. E os indivíduos estão cada vez mais submetidos a uma cultura homogeneizadora característica da sociedade de consumo. No entanto, a materialidade do texto e imagem possibilita múltiplos significados e nos conduz a pensar que os marcadores discursivos dessas matérias foram lidos como produtores de subjetividade que ensinam modos de vida ou criticam modos de vida, tornando-se dispositivos pedagógicos, na perspectiva adotada por Fischer $(2007,2002)$, hierarquizando modos de olhar as questóes da ciência, da técnica, da saúde e do meio ambiente.

Os jornais, aqui considerados documentos e dispositivos pedagógicos, são objetos culturais que difundem a produção de uma época. Assim, ter acesso e ler os jornais, inclusive na escola, significa ampliar nosso repertório de explicações sobre o que nos rodeia, significa ampliar nosso capital cultural (BOURDIEU, 1996), nos abastecendo de recursos para questionar o mundo.

\section{Notas}

1. Deve-se observar que cada seção pode ter de duas a seis matérias por número de jornal.

2. As matérias podem pertencer a um ou mais temas.

\section{Referências}

BARTHES, R. O óbvio e o obtuso: ensaios críticos III. Rio de Janeiro: Nova Fronteira, 1990.

BOURDIEU, P. A economia das trocas linguísticas: o que falar quer dizer. São Paulo: Edusp, 1996. (Clássicos, n. 4).

BUENO, W. C. Jornalismo científico, lobby e poder. Parcerias Estratégicas, Brasília, DF, n. 13, p. 168-200, dez. 2001.

CAVALCANTE, J. O jorna-l como proposta pedagógica. São Paulo: Paulus, 1999.

DIAS, S.O. Terra de papel: amnésias de organicidade. In: REUNIÃO ANUAL DA ANPED, 30., 2007, Caxambu. Anais... Rio de Janeiro: ANPEd, 2007.

FISCHER, R.M.B. O dispositivo pedagógico da mídia: modos de educar 
"Jornal papel": documento e dispositivo pedagógico

na (e pela) TV. Educação \& Pesquisa, São Paulo, v. 28, n. 1, p. 151-162, 2002.

FISCHER, R.M.B. Mídia, máquinas de imagens e práticas pedagógicas. Revista Brasileira de Educação, Rio de Janeiro, v. 12, n. 35, p. 290-299, 2007.

GOMES, I.M.A.M. Dos laboratórios aos jornais: um estudo sobre jornalismo científico. 1995. 185f. Dissertação (Mestrado) - Programa de Pós-Graduação em Letras e Linguística, Universidade Federal de Pernambuco, Recife.

GONÇALVES, E.; CALDAS, G.; PECHULA, M.R. Midia e educação: reflexões sobre o uso pedagógico de textos de divulgação científica. Disponível em: <www.mc.unicamp.br/redpop2011/trabalhos/167. PDF>. Acesso em: 17 abr. 2012.

GOUVÊA, G. A revista Ciência Hoje das Crianças e práticas de leituras do público infantil. In: MASSARANI, L. (Org.). O pequeno cientista amador: a divulgação científica e o público amador. Rio de Janeiro: Vieira e Lent, 2005. p. 47-58.

GOUVÊA, G. As mídias impressas nas pesquisas em Educação e Comunicação - 1991 a 2010. Teias, Rio de Janeiro, v.13, n. 30, p. 43-69, 2012.

GRANGER, G.G. A ciência e as ciências. São Paulo: Unesp, 1994.

LEMKE, J. Multiplying meaning: visual and verbal semiotics in scientific texts. In: MARTIN, J.R.; VEEL, R. (Ed.). Reading science. London: Routledge, 1998. p. 87-114.

MINISTÉRIO DE CIÊNCIA E TECNOLOGIA (MCT) Percepção Pública da Ciência e Tecnologia no Brasil: resultados da enquete de 2010. Brasília, 2010. Disponível <www.museudavida.fiocruz.br/media/enquete2010. pdf>. Acesso em: fevereiro de 2012.

PAROLI, M.R.; ALMEIDA JUNIOR, J.B. Avaliação de programas de uso de jornal em sala de aula oferecidos aos professores por empresas jornalísticas. In: REUNIÃO ANUAL DA ANPED, 29., 2006, Caxambu. Anais... Caxambu: ANPEd, 2006. Disponível <www.anped.org.br/reuniōes/29ra/ trabalhos/.../GT16-2236--Int.pdf>. Acesso em: 19 abr. 2012. 
PRETTO, N.L. A ciência nos meios de comunicação. In: SIMPÓSIO NACIONAL DE ENSINO DE FÍSICA, 9., São Carlos, 1991. Anais... São Paulo: Sociedade Brasileira de Física, 1991.

SCHMIDT, S. Aprendendo a ler nas lentes do jornal. In: REUNIÃO ANUAL DA ANPEd, 30., 2007, Caxambu. Anais... Rio de Janeiro: ANPEd, 2007.

SILVERSTONE, R. Por que estudar a midia? São Paulo: Loyola, 2002.

VAN DIJK, T.A. La noticia como discurso: comprensión, estructura y producción de la información. Barcelona: Paidós, 1990.

ZANCHETA JUNIOR, J. Texto midiático e professores da escola básica. In: REUNIÃO ANUAL DA ANPED, 31., 2008, Caxambu. Anais... Rio de Janeiro: ANPEd, 2008. Disponível em: <www.anped.org.br/ reuniōes/31 ra/1 trabalho/GT16-4754--Int.pdf>. Acesso em: 19 abr. 2012.

Recebido em 12 de maio de 2013.

Aprovado em 11 de outubro de 2013. 